\title{
Article \\ Organophosphate Esters in Indoor Environment and Metabolites in Human Urine Collected from a Shanghai University
}

\author{
Yujie Wang, Ming Yang, Fushun Wang, Xueping Chen, Minghong Wu and Jing Ma *
}

\section{check for} updates

Citation: Wang, Y.; Yang, M.; Wang, F.; Chen, X.; Wu, M.; Ma, J.

Organophosphate Esters in Indoor Environment and Metabolites in Human Urine Collected from a Shanghai University. Int. J. Environ Res. Public Health 2021, 18, 9212. https://doi.org/10.3390/ ijerph18179212

Academic Editors: Elena Rada, Nicola Magnavita and Ashok Kumar

Received: 3 July 2021

Accepted: 27 August 2021

Published: 31 August 2021

Publisher's Note: MDPI stays neutral with regard to jurisdictional claims in published maps and institutional affiliations.

Copyright: (c) 2021 by the authors. Licensee MDPI, Basel, Switzerland. This article is an open access article distributed under the terms and conditions of the Creative Commons Attribution (CC BY) license (https:// creativecommons.org/licenses/by/ $4.0 /)$.
School of Environmental and Chemical Engineering, Shanghai University, Shanghai 200444, China; wyj434880134@shu.edu.cn (Y.W.); mingyang@shu.edu.cn (M.Y.); fswang@shu.edu.cn (F.W.); xpchen@shu.edu.cn (X.C.); mhwu@shu.edu.cn (M.W.)

* Correspondence: jingma@shu.edu.cn

\begin{abstract}
In China, organophosphate esters (OPEs) are widely used in indoor environments. However, there is little information regarding the internal and external exposure of university students to OPEs. Therefore, in this study, nine OPEs and eight OPE metabolites (mOPEs) were measured in indoor dust and atmospheric $\mathrm{PM}_{2.5}$ samples from a university campus in Shanghai, as well as in urine samples collected from the university students. The total concentration of OPEs in the indoor dust in female dormitories $(1420 \mathrm{ng} / \mathrm{g}$ ) was approximately twice that in male dormitories (645 ng/g). In terms of indoor $\mathrm{PM}_{2.5}$, the highest OPE concentration was found in meeting rooms $\left(105 \mathrm{ng} / \mathrm{m}^{3}\right.$, on average), followed by chemical laboratories $\left(51.2 \mathrm{ng} / \mathrm{m}^{3}\right)$, dormitories $\left(44.9 \mathrm{ng} / \mathrm{m}^{3}\right)$, and offices $\left(34.9 \mathrm{ng} / \mathrm{m}^{3}\right.$ ). The total concentrations of the eight mOPEs ranged from $279 \mathrm{pg} / \mathrm{mL}$ to $14,000 \mathrm{pg} / \mathrm{mL}$, with a geometric mean value of $1590 \mathrm{pg} / \mathrm{mL}$. The estimated daily intake values based on the indoor dust and $\mathrm{PM}_{2.5}$ OPE samples (external exposure) were 1-2 orders of magnitude lower than that deduced from the concentration of urinary mOPEs (internal exposure), indicating that dermal contact, dust ingestion, and inhalation do not contribute significantly to OPE exposure in the general population. Moreover, additional exposure routes lead to the accumulation of OPEs in the human body.
\end{abstract}

Keywords: indoor exposure; organophosphate esters; organophosphate ester metabolites; urine; external exposure; internal exposure

\section{Introduction}

The indoor environment has the most direct impact on human health and socioeconomic development [1]. Poor indoor environments increase the burden on human immune systems, leading to asthma, leukemia, immune infertility, lung cancer, and other diseases [2,3]. With increasing industrial development in China, new building materials, decoration materials, and consumer goods are produced and used in large quantities, along with decreased ventilation in energy-efficient buildings [4]. These developments have led to the emergence of organic compounds, such as flame retardants, plasticizers, surface antifouling agents, and surfactants, which were rarely found in Chinese indoor environments decades ago but are now important "modern" indoor exposure factors.

As substitutes of brominated flame retardants, organophosphate esters (OPEs) are widely used as flame retardants, plasticizers, stabilizers, and defoamers for various consumer and industrial products because of their excellent flame retardant performance and flexibility [5]. According to the Chinese Flame Retardant Industry Report (2014-2016), the market share of OPEs produced in China accounts for $30 \%$ of the global flame retardant usage (approximately 620,000 tons) [6]. As OPEs are not chemically bound to the product, they are likely to be released into the ambient environment from the production and use of these materials via volatilization, abrasion, diffusion, and leaching processes [7]. OPEs have been widely detected in various environmental matrices and organisms, including 
the atmosphere [8], water and sediments [9-11], indoor dust [12,13], soil [14], and fish [15]. OPEs in the environment can enter human bodies through dermal contact, dust ingestion, inhalation, and dietary intake, and subsequently undergo accumulation. Considering human breast milk as an example, the mean OPE content in breast milk (3.61 ng/mL) [16] was much higher than that of perfluoroalkyl substances $(0.197 \mathrm{ng} / \mathrm{mL})$ [17] and was close to that of polybrominated diphenyl ethers $(3.81 \mathrm{ng} / \mathrm{g}$, converted from the average lipid content) [18]. Recent studies have found that OPEs have various negative effects, including neurotoxicity, reproductive toxicity, carcinogenicity, endocrine disruption, and genetic toxicity, and their environmental hazard potentials are gradually being confirmed [19,20]. Tri(1,3-dichloro-2-propyl) phosphate (TDCIPP), tris(1-chloro-2-propyl) phosphate (TCIPP), and triphenyl phosphate (TPHP) have mutagenic and carcinogenic effects, which alter human thyroid hormone levels [21,22] and lead to endocrine disruption [23]. As a neurotoxin, TDCIPP [24] can also lead to asthma. Meanwhile, TPHP has been proven to present contact allergy effects and adverse effects on fertility, while TDCIPP has been related to changes in male hormone levels and a decrease in semen quality [25]. As these chemicals are continuously released from OPE-containing materials in enclosed environments, particles are often preferentially adsorbed on indoor dust and air with potential adverse health effects via indoor exposure. Therefore, indoor exposure to OPEs is attracting increasing research attention [26].

With modernization and urbanization, China's indoor environment has undergone tremendous changes; moreover, China presents unique population and exposure characteristics. To date, research on indoor exposure to OPEs has mainly focused on the family environment $[7,27,28]$. However, the information available regarding the indoor operating environment in universities is limited, which includes offices where projectors, computers, printers, and electronic equipment are widely used; chemical analysis laboratories; or crowded university dormitories. Therefore, we need to obtain more data on the characteristics of OPE pollution in different indoor environments to assess the health risks for full-time university students exposed to OPEs. In general, OPEs are easily metabolized into their respective diesters in the human body [29] and produce various phase II conjugate metabolites [30-33]. The existence of OPE metabolites in human urine, which is relatively easy to collect via biological monitoring, could provide information regarding the in vivo exposure dose.

Environmental pollution likely enters the human body through different ways after contact with human body; this is considered as external exposure. On the other hand, initial chemical dosage absorbed and distributed throughout the body via systemic circulation is considered as internal exposure. In this study, indoor dust and fine particulate matter $\left(\mathrm{PM}_{2.5}\right)$ samples were collected from a dormitory, office, meeting room, and chemical laboratory of a university in Shanghai. Urine samples were collected from university students aged 22-30 years. Nine OPEs and eight mOPEs were selected as target compounds. The purpose of this study was to (a) determine the concentration, profile, and lifetime carcinogenic risk of OPEs in different indoor environments of a university and (b) investigate the levels of mOPEs in the urine samples of university students, infer the actual exposure level according to the internal exposure dose of mOPEs, and compare this value with the estimated external exposure level.

\section{Materials and Methods}

\subsection{Sample Collection and Chemicals}

Sampling was conducted from December 2017 to July 2018 at Shanghai University, which is located in the suburban area of Shanghai, China. $\mathrm{PM}_{2.5}$ samples $(n=37$ in total) were randomly selected from offices $(n=12)$, chemical analysis laboratories $(n=9)$, dormitories $(n=12)$, and meeting rooms $(n=4)$. Quartz filters (QMA, Whatman, Boston, MA, USA) with a medium flow air particulate matter sampler equipped with a cutting head for $2.5 \mu \mathrm{m}$ particles (TH-150, Tianhong, Wuhan, PRC) were applied at a sampling flow of $0.1 \mathrm{~m}^{3} / \mathrm{min}$ for $8 \mathrm{~h}$. Indoor dust samples were collected from female $(n=48)$ and 
male dormitories $(n=47)$. A household vacuum cleaner was used to collect indoor dust from apartment dormitories (Figure S1 in the Supporting Information). All the collected quartz filters and screened dust samples were stored in a freezer at $-29^{\circ} \mathrm{C}$ for pretreatment. Morning urine samples $(n=60)$ were collected from female $(n=24)$ and male university students $(n=36)$ recruited from Shanghai University. The study protocol was reviewed and approved by the Ethics Committee of Shanghai Zhabei District Shibei Hospital. Each volunteer was asked to fill out a questionnaire, including information such as age, sex, smoking status, allergy history, and use of electronic devices. The collected urine samples were immediately transferred to a laboratory freezer maintained at $-29^{\circ} \mathrm{C}$.

Nine triester OPEs and eight diester mOPEs were analyzed: triethyl phosphate (TEP), tri-n-propyl phosphate (TPP), tris(2-butoxyethyl) phosphate (TBOEP), tris(2-ethylhexyl) phosphate (TEHP), TCIPP, TDCIPP, TPHP, tris(methylphenyl) phosphate (TMPP), tris(2chloroethyl) phosphate (TCEP), diphenyl phosphate (DPHP), di(methylphenyl) phosphate (DMPP), diethyl phosphate (DEP), bis(2-ethylhexyl) phosphate (BEHP), bis(2-butoxyethyl) hydrogen phosphate (BBOEP), bis(2-chloroethyl) phosphate (BCEP), bis-(1-chloro-2-propyl) phosphate (BCIPP), and bis(1,3-dichloro-2-propyl) phosphate (BDCIPP). More details are provided in the Supporting Information (Table S1).

\subsection{Chemical Analysis}

OPEs and mOPEs were extracted from indoor dust $/ \mathrm{PM}_{2.5}$ and human urine samples, respectively. Nine OPEs were analyzed using a gas chromatography-mass spectrometer (GC/MS, 7890A/5975C, Agilent, CA, USA). Eight mOPEs were analyzed using an Agilent 1260 liquid chromatograph coupled with an Agilent 6460 triple quadrupole mass spectrometer (Agilent, Palo Alto, CA, USA). Details regarding sample preparation and instrumental analysis are provided in the Supporting Information.

\subsection{Quality Assurance and Quality Control}

Every 10 samples were equipped with a procedural blank to monitor contamination and environmental interference during the experimental operation. The limit of quantification (LOQ) was set to three times the standard deviation of the blank samples. The recoveries of the two internal standards of OPEs were as follows: $82 \% \pm 19 \%$ for $\mathrm{d}_{15}$-TPHP, and $89 \% \pm 20 \%$ for triamyl phosphate. The recoveries of deuterated internal standards for mOPEs were as follows: $90 \% \pm 18 \%$ for $d_{10}$-DPHP, $93 \% \pm 16 \%$ for $d_{10}$-BDCIPP, and $91 \% \pm 20 \%$ for $\mathrm{d}_{8}$-BBOEP. The LOQ values of the OPEs in the indoor dust and $\mathrm{PM}_{2.5}$ were $0.24-21.5 \mathrm{ng} / \mathrm{g}$ and $10.0-1340 \mathrm{pg} / \mathrm{m}^{3}$, respectively. Meanwhile, the LOQ of the mOPEs in the urine samples ranged from $0.84 \mathrm{pg} / \mathrm{mL}$ to $21.9 \mathrm{pg} / \mathrm{mL}$.

\subsection{Statistical Analysis}

Considering biological diversity, the specific gravity (SG) of the urine was used to correct the concentration of the target substance in the urine. The concentration of the object below the detection limit was set to 0 . Further, $1 / 2$ LOQ was used as the substitute for concentrations below the LOQ. Positive matrix factorization (PMF) was used to estimate the source information of the target analytes in different media. Statistical analyses were performed using Origin 8.0 (OriginLab Corporation, Northampton, MA, USA) and SPSS (version 19.0, SPSS Inc., Chicago, IL, USA).

\section{Results and Discussion}

\subsection{Concentration Distribution of OPEs in Indoor Dust and Atmospheric $P M_{2.5}$}

Seven of the nine targeted OPE compounds were found in both the indoor dust and $\mathrm{PM}_{2.5}$ at detection rates ranging from $78-99 \%$ and $97-100 \%$, respectively, indicating that OPEs are widespread in indoor campus environments. Therefore, $\Sigma$ OPEs are considered as the sum of concentrations of these seven individual compounds (TEP, TCEP, TCIPP, TDCIPP, TPHP, TBOEP, and TMPP). The concentrations of $\Sigma$ OPEs in indoor dust and $\mathrm{PM}_{2.5}$ are shown in Figure 1, and the distribution of the OPE data is listed in Table S2. The 
concentration range of $\Sigma$ OPEs was $0.39-6480 \mathrm{ng} / \mathrm{g}$ (mean value: $1040 \mathrm{ng} / \mathrm{g}$ ) in the indoor dust samples. Specifically, TPHP $(39.0 \%)$ was the predominant compound, followed by TDCIPP (28.1\%). A similar profile was observed for the indoor dust of a Canadian e-waste dismantling facility [34]; e-waste recycling regions in Guangdong, China [35]; and several microenvironmental floors in Beijing, China [36]. The concentration range of $\Sigma$ OPEs was $0.015-287 \mathrm{ng} / \mathrm{m}^{3}$ (mean value: $50 \mathrm{ng} / \mathrm{m}^{3}$ ) in the indoor $\mathrm{PM}_{2.5}$, wherein TCEP $(40.8 \%$ ) was the predominant compound, followed by TBOEP (29.0\%). A similar pattern was observed in the indoor $\mathrm{PM}_{2.5}$ of classrooms in Norway [37]. Cl-OPEs presented the highest contribution to indoor dust (51.0\%) and $\mathrm{PM}_{2.5}$ samples (65.2\%). The $\Sigma \mathrm{OPE}$ concentration measured in the female dormitory $(1420 \mathrm{ng} / \mathrm{g})$ was approximately twice that measured in the male dormitory $(645 \mathrm{ng} / \mathrm{g})$. Aryl-OPEs and Cl-OPEs presented higher contributions in female dormitories, whereas Cl-OPEs were dominant in male dormitories (Figure 1). TPHP (48.9\%), TDCIPP $(23.8 \%)$, and TCIPP $(10.0 \%)$ presented the highest contributions to the dust in the female dormitories, while TDCIPP (37.7\%), TCEP $(22.1 \%)$, and TCIPP $(11.5 \%)$ were dominant in the male dormitories. TPHP has been detected in nail polish, and DPHP was measured in urine samples from female participants who applied nail polish [38]. This indicates that the different lifestyles of males and females can affect their exposure to the indoor environment. The concentrations of OPEs in indoor dust have been reported in many countries (Table S3). In general, the concentrations of OPEs in this study were similar to those reported for Kuwait, New Zealand, Germany, and Saudi Arabia [39-42], which were one order of magnitude lower than those reported in developed countries, such as the United Kingdom, Sweden, and Japan [43-45], and nearly one order of magnitude higher than those reported in Pakistan, Egypt, and Nepal [13,39,46].

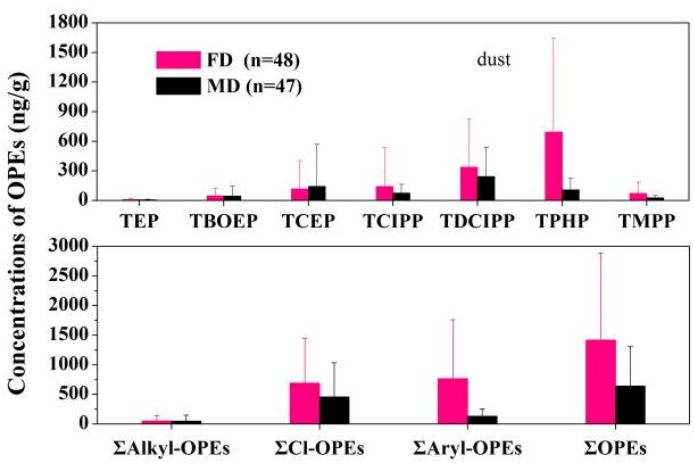

(a)

$$
\text { हैं }
$$

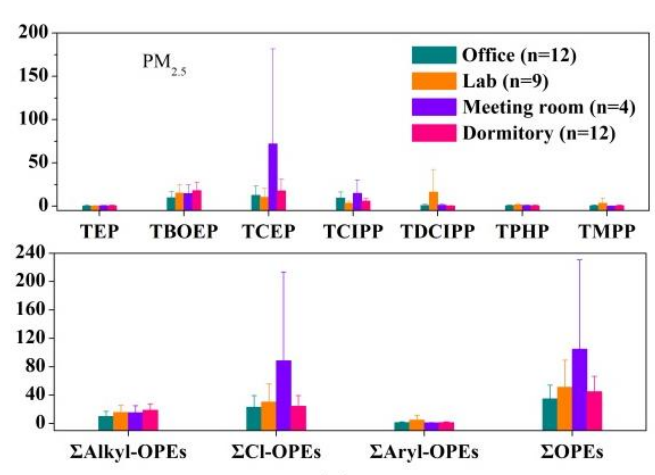

(c)

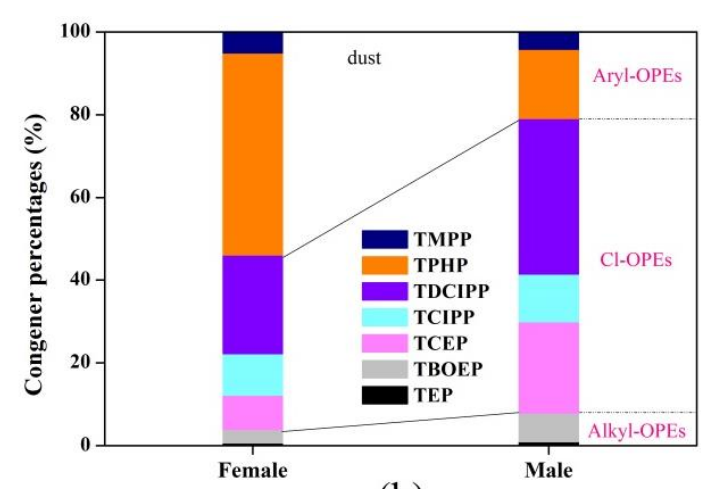

(b)

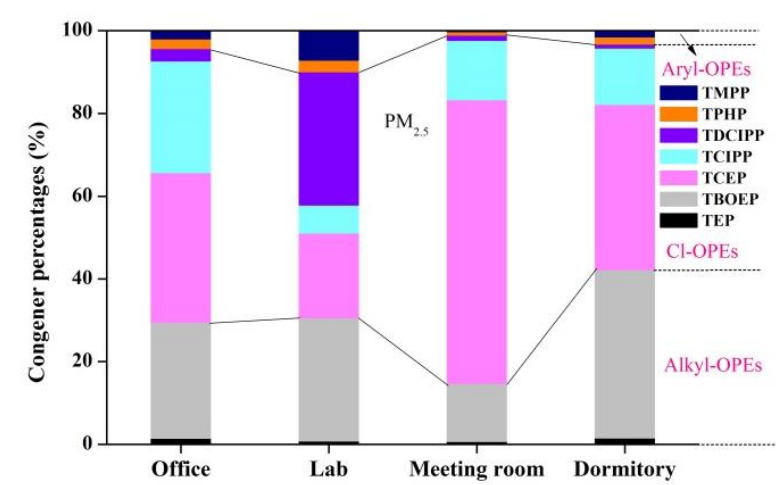

(d)

Figure 1. (a) Concentrations of OPEs in indoor dust samples from male dormitories (MD) and female dormitories (FD) (ng/g); (b) Composition of OPEs in indoor dust samples from male dormitories (MD) and female dormitories (FD) (\%); (c) Concentrations of OPEs in indoor atmospheric $\mathrm{PM}_{2.5}$ samples from different functional areas $\left(\mathrm{ng} / \mathrm{m}^{3}\right)$; $(\mathbf{d}) \mathrm{The}$ composition of OPEs in indoor atmospheric $\mathrm{PM}_{2.5}$ samples from different functional areas (\%). 
Regarding indoor $\mathrm{PM}_{2.5}$, the highest concentration of $\Sigma \mathrm{OPEs}$ was found in meeting rooms $\left(105 \mathrm{ng} / \mathrm{m}^{3}\right.$, on average), followed by chemical laboratories $\left(51.2 \mathrm{ng} / \mathrm{m}^{3}\right)$, dormitories $\left(44.9 \mathrm{ng} / \mathrm{m}^{3}\right)$, and offices $\left(34.9 \mathrm{ng} / \mathrm{m}^{3}\right)$. Cl-OPEs were the dominant OPE compounds in indoor air $\mathrm{PM}_{2.5}$, followed by alkyl-OPEs. The OPE profiles were similar among offices (TCEP, 36.2\%; TBOEP, 28.0\%; and TCIPP, 27.0\%), meeting rooms (TCEP, 68.6\%; TCIPP, 14.3\%; and TBOEP, $14.0 \%$ ), and dormitories (TBOEP, 40.7\%; TCEP, 39.9\%; and TCIPP, $13.6 \%$ ), but different from those in laboratories (TDCIPP, 32.2\%; TBOEP, 29.8\%; and TCEP, $20.6 \%$ ). Previous studies have mostly focused on indoor air in homes and workplaces (e.g., offices, laboratories, and shops); for comparison, these values are listed in Table S4. In general, the OPE concentration (mean value: $50 \mathrm{ng} / \mathrm{m}^{3}$, range: $0.015-287 \mathrm{ng} / \mathrm{m}^{3}$ ) in this study was similar to the levels of $\Sigma$ OPEs reported in Switzerland $\left(3.90-270 \mathrm{ng} / \mathrm{m}^{3}\right)$ [47] and Spain (1.59-202 ng $/ \mathrm{m}^{3}$ ) [48], but was several orders of magnitude lower than those reported in developed countries, such as Sweden $\left(101-1900 \mathrm{ng} / \mathrm{m}^{3}\right)$ [49], the United States (2220-1,040,000 $\left.\mathrm{ng} / \mathrm{m}^{3}\right)$ [50], and Vietnam $\left(540-13,000 \mathrm{ng} / \mathrm{m}^{3}\right)$ [51].

\subsection{Source Analysis for Indoor Dust and Atmospheric $P M_{2.5}$}

The OPE compound concentrations were determined using the United States Environmental Protection Agency (USEPA) PMF 5.0 model to evaluate the contribution of OPE sources to the indoor environments of the university (additional details in the Supporting Information (Table S9)). According to the PMF software analysis, three key factors were extracted from the indoor dust and $\mathrm{PM}_{2.5}$ in the study area. For both indoor dust and $\mathrm{PM}_{2.5}$ (Figure 2), the markers of factor 1 were mainly TCIPP and TCEP. Specifically, large amounts of TCEP are used in buildings, and may remain active sources for several years [52]. Meanwhile, TCIPP is a common substitute for pentabromodiphenyl ether in polyurethane foam [19]. Thus, it was preliminarily speculated that factor 1 was indicative of the release from building materials and furniture. For these OPEs, inhalation is expected to be a more dominant intake pathway than dust ingestion and dermal contact [53]. Factor 2 was characterized by high loadings of TDCIPP, TPHP, and TMPP. TDCIPP is commonly used as an additive in polyurethane foam padding used in furniture, children's foam products, and automobile upholstery $[54,55]$. Frequent use of electronics was associated with higher TDCIPP hand wipe levels [56]. TPHP is one of the most effective flame retardants for many polymers and can be used in hydraulic fluids [52] and polyvinyl chloride (PVC) [57]. Zheng et al. [35] found that TPHP was the main OPE in the indoor dust at e-waste recycling stations in South China. TMPP can also be used in hydraulic fluids [52] and PVC [57]; it has also been reported to be the main organophosphate flame retardant in e-waste disposal sites in southern China [58]. Therefore, factor 2 was likely attributed to the use of electronic equipment. Factor 3 was heavily loaded with TBOEP and TEP. Alkyl-OPEs are mainly used as plasticizers in unsaturated polyester resins, cellulose acetate, PVC, synthetic rubber, and other materials [59]. In addition, they can also be used as defoaming agents in coatings, hydraulic oils, and floor waxes [60]. TBOEP has been reportedly used as an additive in floor polishing in school indoor environments [37]. Therefore, factor 3 was speculated to be indicative of the use of decoration materials or other consumer goods. 


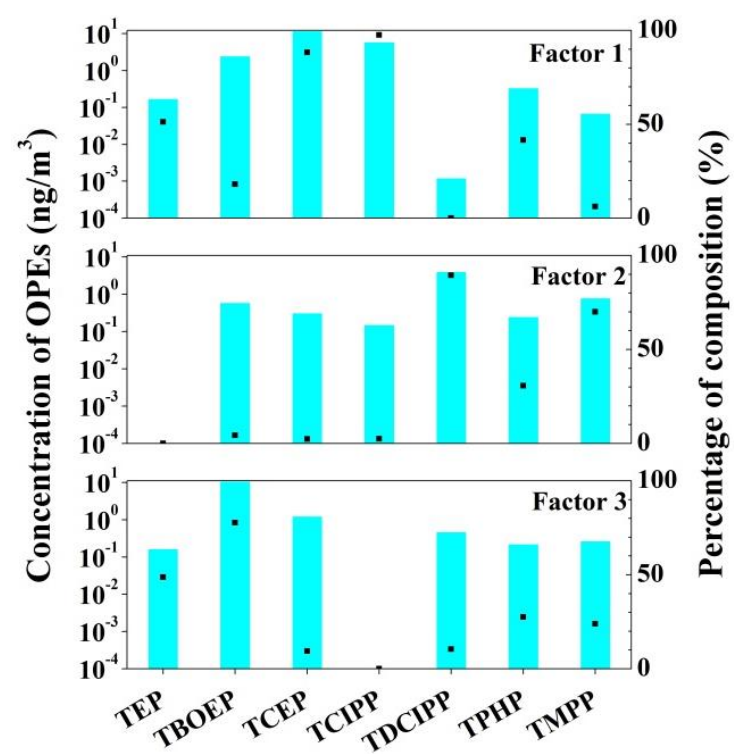

(a)

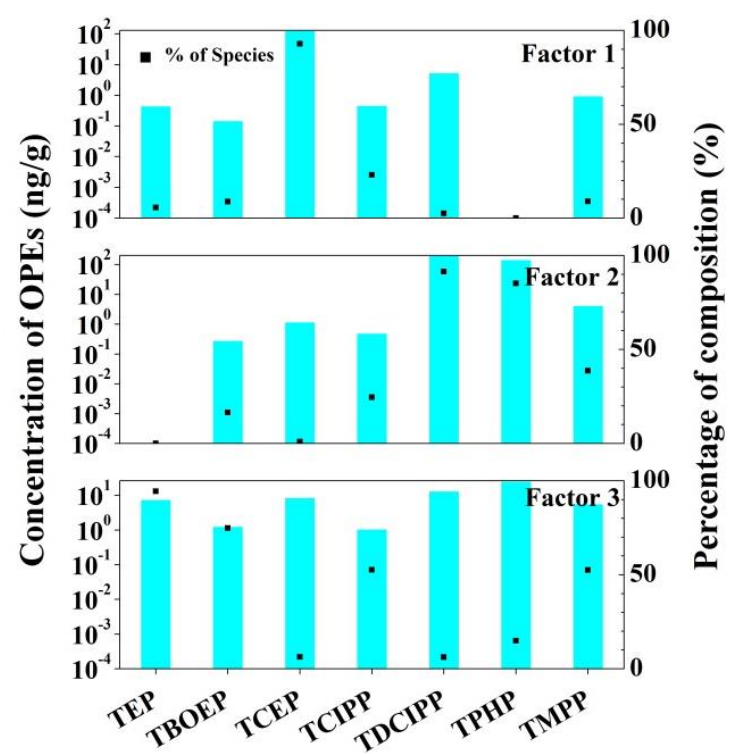

(b)

Figure 2. (a) The source distribution of OPEs in indoor atmospheric $\mathrm{PM}_{2.5}$ (left column: contribution of various factors to the concentration of OPEs $\left(\mathrm{ng} / \mathrm{m}^{3}\right)$; right column: impact ratio of various factors on OPEs (\%)); (b) The source distribution of OPEs in indoor dust (left column: contribution of various factors to the concentration of OPEs (ng/g); right column: impact ratio of various factors on OPEs $(\%))$.

\subsection{Concentration Distribution of mOPEs in Human Urine Samples}

The SG-adjusted geometric mean (GM) concentrations and profiles of eight mOPEs in the collected urine samples are illustrated in Figure 3, and the distribution of the mOPE data is listed in Table S5. Aryl-mOPEs (DPHP, 78.3\%) and alkyl-mOPEs (DEP, 91.7\%; BBOEP, $78.3 \%$; and BEHP, $75.0 \%$ ) presented high detection frequencies in all urine samples. Cl-mOPEs were observed with detection frequencies of less than $50 \%$, for which similar patterns were reported for the detection frequencies of urinary mOPEs in a general exposed population in China [61]. The total concentrations of the eight mOPEs ( $\Sigma$ mOPEs) ranged from $279 \mathrm{pg} / \mathrm{mL}$ to $14,000 \mathrm{pg} / \mathrm{mL}$, with a GM value of $1590 \mathrm{pg} / \mathrm{mL}$. The $\Sigma \mathrm{mOPE}$ concentrations in the female urine samples were higher than those in the male urine samples, but the difference was not significant $(p>0.05)$. Alkyl-mOPEs were the predominant mOPEs in both male and female urine samples. The proportion of dominant mOPE monomers in the female urine samples was as follows: DEP $(40.8 \%)>$ DPHP $(26.7 \%)>$ BCEP $(12.6 \%)$. In contrast, in the male urine samples, the proportion of dominant mOPE monomers was DEP $(41.9 \%)>$ BCEP $(17.8 \%)>$ BBOEP $(15.4 \%)$. It has been reported that there are significant differences between males and females in terms of exposure, toxicokinetics, and reactions to chemicals $[62,63]$. The results in this study show that, except for DPHP, gender differences had no significant effect on the distribution of mOPEs in urine samples. However, the small sample size analyzed in these studies may be subject to certain biases. 


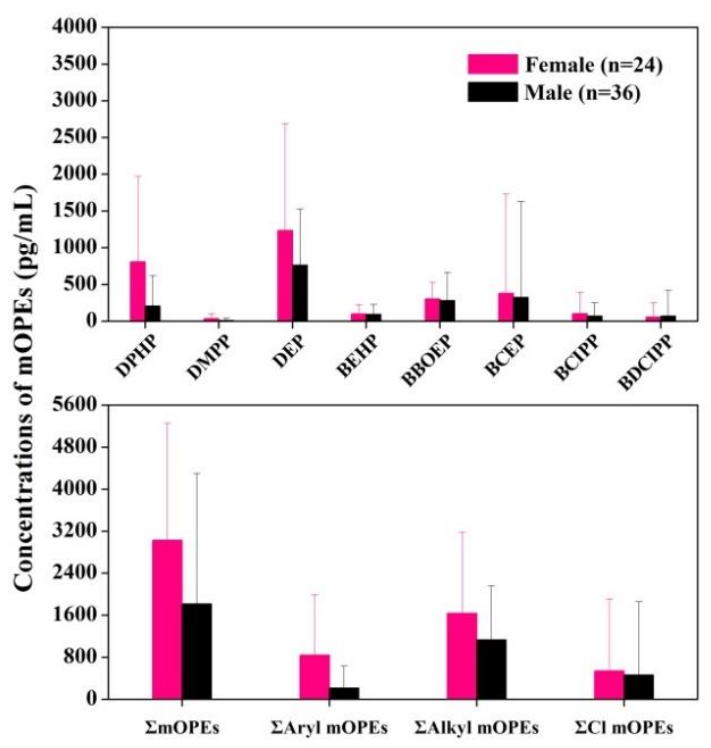

(a)

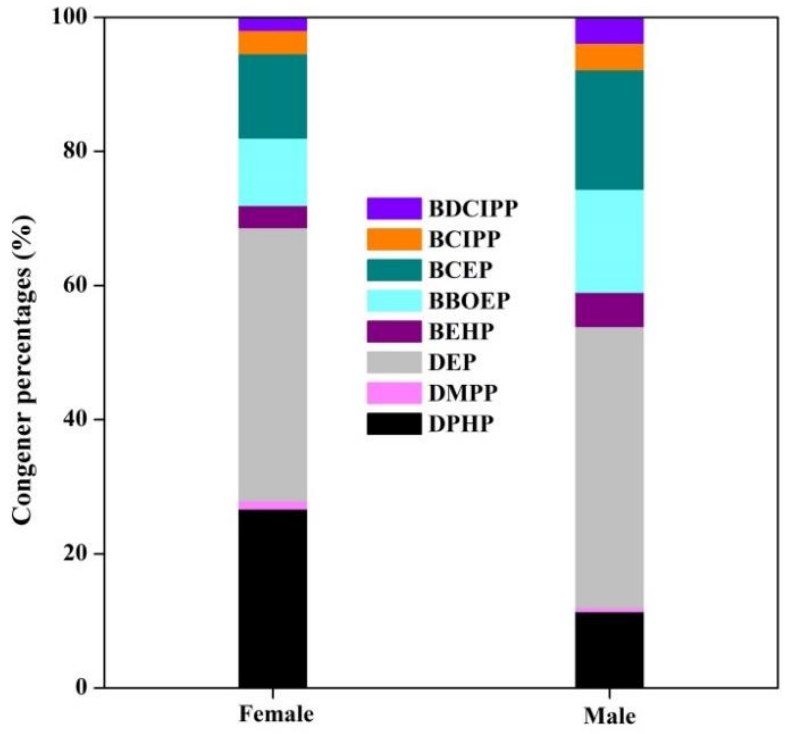

(b)

Figure 3. (a) Concentrations of mOPEs in male and female urine samples (pg/mL); (b) Composition of mOPEs in male and female urine samples (\%).

The main mOPE monomers reported in China and globally were BDCIPP and DPHP, which were 2-3 orders of magnitude higher than the concentration levels in this study, indicating that the internal exposure degrees of TDCIPP and TPHP in this study area were relatively low (Table S6). This might be attributed to the different indoor uses of OPEs; for example, the United States has a high demand for flame retardant interior furniture $[31,64]$. Although organic toxic pollutants in the environment may form pollution sinks in the indoor environment, pollutants such as OPEs physically added to the products may function as a pollution source. We also compared the urinary mOPE concentrations with the concentrations of their corresponding parent OPEs in indoor environments on campus and found no significant correlation (Tables S7 and S8). This may be because indoor atmospheric particulate matter or dust concentrations only reflect the exposure pathways of dermal contact and respiratory intake, whereas, for the general population, dietary intake is the predominant pathway. In addition, there are differences in the metabolic mechanism of each OPE upon entry into the human body [65].

\subsection{Risk Assessment of OPEs}

Details regarding the estimated daily intake (EDI), hazard index (HI), and carcinogenic risk (CR) of OPEs via air and dust exposure are provided in the Supporting Information

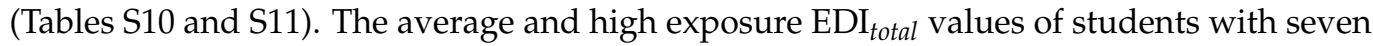
OPEs, as estimated by indoor air intake, dust intake, and skin absorption, were $5.10 \mathrm{ng} / \mathrm{kg}$ $\mathrm{bw} / \mathrm{d}$ and $14.0 \mathrm{ng} / \mathrm{kg} \mathrm{bw} / \mathrm{d}$, respectively. The daily exposure dose of OPEs calculated by indoor air intake and dust intake was similar to the EDI value of the drinking water intake of OPEs reported in New York [66], and approximately 10 times lower than the OPE EDI values of indoor air intake and dust intake in the United States [50]. The EDI ${ }_{\text {inhalation }}$ value of OPEs was higher than that of the indoor air $\mathrm{PM}_{2.5}$ of subway station [48], while $\mathrm{EDI}_{\text {ingestion }}$ was lower than that in the indoor dust in Guangzhou [7]. In general, the EDIs of OPEs in indoor air and dust in this study were in the low-middle level. The HI value of the OPE monomers with non-potential carcinogenic risk was less than 1 , and the $C R$ value of the OPE monomers with a potential carcinogenic risk was less than $1 \times 10^{-6}$, which indicates that there was no potential health risk when exposed to indoor air $\mathrm{PM}_{2.5}$ and indoor dust in this university.

mOPEs in urine are non-invasive biomarkers that can be used to identify and quantify human exposure to OPEs. They provide comprehensive information on system load, 
including all types of sources and exposure routes (such as inhalation, dermal contact, and oral ingestion), and can be used to quantify personal exposure. Biotransformation can be an important determinant of the toxicological effects and bioaccumulation of xenobiotics [32]. Despite the limitations of the OPE kinetic or metabolic data in terms of the human body [67], metabolism studies of five mOPEs (TCEP, TCIPP, TDCIPP, TPHP, and TBOEP) in human liver microsomes (HLMs) and S9 fractions provided some evidence of their bioavailability and toxicity in humans [32]. Herein, the individual internal exposure OPE doses according to the concentration of related mOPEs in the urine samples were estimated

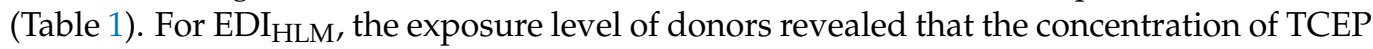
was the highest (103 $\mathrm{ng} / \mathrm{kg}$ bw/day), followed by TPHP ( $52.5 \mathrm{ng} / \mathrm{kg} \mathrm{bw} /$ day), TBOEP ( $8.07 \mathrm{ng} / \mathrm{kg} \mathrm{bw} /$ day), TCIPP (4.97 ng/kg bw/day), and TDCIPP (3.57 ng/kg bw/day). For EDI S $_{\text {, }}$ this order was TPHP (118 $\mathrm{ng} / \mathrm{kg}$ bw/day), TCEP (55.8 $\mathrm{ng} / \mathrm{kg}$ bw/day), TBOEP (40.9 ng/kg bw/day), TCIPP (5.86 ng/kg bw/day), and TDCIPP (2.42 ng/kg bw/day). All the estimated HI levels were less than 1, suggesting that there was no significant risk of exposure to OPEs in this study.

In addition, it was found that the OPE EDI values estimated by exposure to indoor dust and $\mathrm{PM}_{2.5}$ (external exposure) were 1-2 orders of magnitude lower than that deduced from the concentration of urinary mOPEs (internal exposure), indicating that dermal contact, dust ingestion, and inhalation do not contribute significantly to OPE exposure in the general population. Studies have found that dietary intake is another important means of human exposure to OPEs [68]. TCEP has been detected in eggs from southern China at a detection rate of $100 \%$ [69]. A comprehensive investigation of OPE concentrations in Chinese food indicated that TCEP (mean value: $0.74-29.8 \mathrm{ng} / \mathrm{g}$ ) was the most important OPE in various food categories, including rice, cereals, vegetables, meat, and fruits [70]. In China, rice intake is considered to be the main means of exposure to OPEs in foods, as it presents the highest contribution to total intake, accounting for approximately $60 \%$ [71]. The highest levels of OPEs have been reported in cereals, which may be the main path of dietary intake for the Chinese population [72]. 
Table 1. EDIs (ng/kg bw/d), HI, and CR from the exposure of OPEs.

\begin{tabular}{|c|c|c|c|c|c|c|c|c|c|c|c|c|}
\hline Analytes & & TEP & TBOEP & TCEP & TCIPP & TDCIPP & TPHP & TMPP & ¿OPEs & $\begin{array}{l}\text { Alkyl- } \\
\text { OPEs }\end{array}$ & Cl-OPEs & Aryl-OPEs \\
\hline RfD & & $1.30 \times 10^{5}$ & $1.50 \times 10^{4}$ & $7.00 \times 10^{3}$ & $1.00 \times 10^{4}$ & $2.00 \times 10^{4}$ & $7.00 \times 10^{4}$ & $1.30 \times 10^{4}$ & & & & \\
\hline SFO & & & & $2.00 \times 10^{-8}$ & & $3.10 \times 10^{-8}$ & & & & & & \\
\hline \multicolumn{13}{|c|}{ EDIs (ng/kg bw/d), HI and CR from the exposure of OPEs in indoor dust and air } \\
\hline \multirow{2}{*}{$\mathrm{EDI}_{\text {ingestion }}$} & Average & $1.33 \times 10^{-3}$ & $5.24 \times 10^{-3}$ & $6.45 \times 10^{-3}$ & $5.30 \times 10^{-3}$ & $3.36 \times 10^{-2}$ & $3.29 \times 10^{-2}$ & $5.88 \times 10^{-3}$ & $1.61 \times 10^{-1}$ & $7.26 \times 10^{-3}$ & $6.95 \times 10^{-2}$ & $3.76 \times 10^{-2}$ \\
\hline & High & $2.95 \times 10^{-3}$ & $1.69 \times 10^{-2}$ & $4.81 \times 10^{-2}$ & $4.04 \times 10^{-2}$ & $1.08 \times 10^{-1}$ & $1.50 \times 10^{-1}$ & $1.85 \times 10^{-2}$ & $3.85 \times 10^{-1}$ & $1.99 \times 10^{-2}$ & $1.97 \times 10^{-1}$ & $1.69 \times 10^{-1}$ \\
\hline \multirow{2}{*}{$\mathrm{EDI}_{\text {dermal adsorption }}$} & Average & $1.41 \times 10^{-3}$ & $5.55 \times 10^{-3}$ & $6.84 \times 10^{-3}$ & $5.62 \times 10^{-3}$ & $3.56 \times 10^{-2}$ & $3.49 \times 10^{-2}$ & $6.24 \times 10^{-3}$ & $1.71 \times 10^{-1}$ & $7.70 \times 10^{-3}$ & $7.37 \times 10^{-2}$ & $3.99 \times 10^{-2}$ \\
\hline & $n$ High & $3.79 \times 10^{-3}$ & $2.17 \times 10^{-2}$ & $6.18 \times 10^{-2}$ & $5.18 \times 10^{-2}$ & $1.39 \times 10^{-1}$ & $1.93 \times 10^{-1}$ & $2.37 \times 10^{-2}$ & $4.95 \times 10^{-1}$ & $2.55 \times 10^{-2}$ & $2.53 \times 10^{-1}$ & $2.17 \times 10^{-1}$ \\
\hline EDI $_{\text {inhalation }}$ & High & $1.54 \times 10^{-1}$ & 3.79 & 5.34 & 1.98 & 1.22 & $2.56 \times 10^{-1}$ & $3.54 \times 10^{-1}$ & $1.31 \times 10^{1}$ & 3.95 & 8.53 & $6.10 \times 10^{-1}$ \\
\hline \multirow{2}{*}{$\mathrm{EDI}_{\text {total }}$} & Average & $5.52 \times 10^{-2}$ & 1.56 & 1.48 & $7.33 \times 10^{-1}$ & $1.73 \times 10^{-1}$ & $1.49 \times 10^{-1}$ & $5.62 \times 10^{-2}$ & 5.10 & 1.69 & 3.30 & $2.24 \times 10^{-1}$ \\
\hline & High & $1.60 \times 10^{-1}$ & 3.83 & 5.45 & 2.07 & 1.46 & $5.99 \times 10^{-1}$ & $3.97 \times 10^{-1}$ & $1.40 \times 10^{1}$ & 3.99 & 8.98 & $9.95 \times 10^{-1}$ \\
\hline \multirow{2}{*}{$\mathrm{HI}$} & Average & $4.25 \times 10^{-7}$ & $1.04 \times 10^{-4}$ & $2.11 \times 10^{-4}$ & $7.33 \times 10^{-5}$ & $8.66 \times 10^{-6}$ & $2.13 \times 10^{-6}$ & $4.33 \times 10^{-6}$ & & & & \\
\hline & High & $1.23 \times 10^{-6}$ & $2.55 \times 10^{-4}$ & $7.78 \times 10^{-4}$ & $2.07 \times 10^{-4}$ & $7.32 \times 10^{-5}$ & $8.55 \times 10^{-6}$ & $3.05 \times 10^{-5}$ & & & & \\
\hline \multirow{2}{*}{$\mathrm{CR}$} & Average & & & $2.96 \times 10^{-8}$ & & $5.37 \times 10^{-9}$ & & & & & & \\
\hline & High & & & $1.09 \times 10^{-7}$ & & $4.54 \times 10^{-8}$ & & & & & & \\
\hline \multicolumn{13}{|c|}{ EDIs (ng/kg bw/day) and HI calculated under various assumptions of urine excretion of OPEs in different sex groups } \\
\hline $\mathrm{EDI}_{\text {total }}$ & Female & & 6.92 & 88.8 & 4.26 & 3.06 & 45 & & 148 & & & \\
\hline \multirow{2}{*}{$\mathrm{HI}$} & Male & & $6.15 \times 10^{-4}$ & $1.69 \times 10^{-2}$ & $5.68 \times 10^{-4}$ & $2.04 \times 10^{-4}$ & $8.58 \times 10^{-4}$ & & $1.92 \times 10^{-2}$ & & & \\
\hline & Female & & $4.61 \times 10^{-4}$ & $1.27 \times 10^{-2}$ & $4.26 \times 10^{-4}$ & $1.53 \times 10^{-4}$ & $6.43 \times 10^{-4}$ & & $1.44 \times 10^{-2}$ & & & \\
\hline \multirow{2}{*}{$\mathrm{CR}$} & Male & & & $2.36 \times 10^{-6}$ & & $1.26 \times 10^{-7}$ & & & & & & \\
\hline & Female & & & $1.78 \times 10^{-6}$ & & $9.49 \times 10^{-8}$ & & & & & & \\
\hline \multicolumn{13}{|c|}{ Daily intakes estimated based on $F_{u e}$ values of OPEs in human S9 fraction system (EDI $\left.{ }_{S 9}\right)$} \\
\hline \multirow{2}{*}{$\mathrm{EDI}_{\text {total }}$} & Male & & 46.7 & 63.8 & 6.7 & 2.76 & 135 & & 255 & & & \\
\hline & Female & & 35 & 47.8 & 5.02 & 2.07 & 101 & & 191 & & & \\
\hline \multirow{2}{*}{$\mathrm{HI}$} & Male & & $3.11 \times 10^{-3}$ & $9.11 \times 10^{-3}$ & $6.70 \times 10^{-4}$ & $1.38 \times 10^{-4}$ & $1.93 \times 10^{-3}$ & & $1.50 \times 10^{-2}$ & & & \\
\hline & Female & & $2.33 \times 10^{-3}$ & $6.83 \times 10^{-3}$ & $5.02 \times 10^{-4}$ & $1.03 \times 10^{-4}$ & $1.45 \times 10^{-3}$ & & $1.12 \times 10^{-2}$ & & & \\
\hline \multirow{2}{*}{$\mathrm{CR}$} & Male & & & $1.28 \times 10^{-6}$ & & $8.56 \times 10^{-8}$ & & & & & & \\
\hline & Female & & & $9.56 \times 10^{-7}$ & & $6.42 \times 10^{-8}$ & & & & & & \\
\hline
\end{tabular}




\section{Conclusions}

The OPE concentrations and EDIs in the indoor dust and atmospheric $\mathrm{PM}_{2.5}$ samples obtained in this study were relatively low, as compared with global levels. Specifically, the concentration level of mOPEs was 2-3 orders of magnitude lower than that reported in domestic and foreign studies. Three key contributing factors were extracted using the PMF model of the OPE concentrations in the indoor dust and $\mathrm{PM}_{2.5}$ samples, revealing that building materials and furniture, electronic equipment, and the use of decoration materials and other consumer goods were the main contributing factors. The OPE EDI values estimated using the OPE indoor dust and $\mathrm{PM}_{2.5}$ samples were 1-2 orders of magnitude lower than that deduced by urinary mOPEs. These findings can act as a foundation for the establishment of a comprehensive evaluation mechanism for indoor and outdoor environments in the future. Upon comparing internal and external exposure, it was found that dermal contact, dust ingestion, and inhalation did not contribute significantly to OPE exposure in the general population. Instead, dietary intake may be the main exposure pathway contributing to the health risks of the general population. Full-time college students typically reside and study on campus for several years, which presents a good research object for studying the health effects of indoor exposure. In the future, extensive research should be carried out, including on dietary exposure, in order to obtain more accurate data on the exposure to OPEs in the general population.

Supplementary Materials: The following are available online at https://www.mdpi.com/article/10 .3390/ijerph18179212/s1, Figure S1: Sample collection from indoor environment, Table S1: Designation and structural formula of OPEs and its metabolites (mOPEs), Table S2: Distribution of OPEs concentrations found in indoor dust $(\mathrm{n}=95)$ and airborne $\mathrm{PM}_{2.5}(\mathrm{n}=37)$, Table S3: Concentrations of OPEs in indoor dust worldwide (ng/g), Table S4: Concentrations of OPEs in indoor air (gas and/or PM phase) samples worldwide $\left(\mathrm{ng} / \mathrm{m}^{3}\right)$, Table S5: Distribution of SG adjusted OPE metabolite concentrations found in urine $(\mathrm{n}=60)$ from Shanghai $(\mathrm{pg} / \mathrm{mL})$, Table S6: SG adjusted geometric mean or median concentrations of urinary mOPEs worldwide $(\mathrm{pg} / \mathrm{mL})$, Table S7: Correlation coefficient of mOPEs in human urine and OPEs in indoor dust, Table S8: Correlation coefficients of mOPEs in human urine and OPEs in indoor atmospheric $\mathrm{PM}_{2.5}$ samples, Table S9: The parameters of input files in PMF, Table S10: Exposure parameters for children and adults, and Table S11: Parameters used for calculation of total EDI and HI of OPEs in China.

Author Contributions: The authors contributed according to their research specialty. Y.W.: sample collection and preparation, data analysis, and writing the original manuscript. M.Y., F.W., X.C., M.W. and J.M.: reviewing, editing and supervision. All authors have read and agreed to the published version of the manuscript.

Funding: This research was supported by the National Natural Science Foundations of China (Nos. 21477072 and 31971523).

Institutional Review Board Statement: The study was conducted according to the guidelines of the Declaration of Helsinki and approved by the Ethics Committee of Shanghai Zhabei District Shibei Hospital (2014002 and 25 February 2014).

Informed Consent Statement: Informed consent was obtained from all subjects that participated in the study.

Data Availability Statement: All data generated and analyzed during this study are included in this published article and its supplementary information files.

Conflicts of Interest: The authors declare no conflict of interest. 


\section{References}

1. Harada, K.; Hasegawa, A.; Wei, C.N.; Minamoto, K.; Noguchi, Y.; Hara, K.; Matsushita, O.; Noda, K.; Ueda, A. A review of Indoor Air Pollution and Health Problems from the Viewpoint of Environmental Hygiene: Focusing on the Studies of Indoor Air Environment in Japan Compared to Those of Foreign Countries. J. Health Sci. 2010, 56, 488-501. [CrossRef]

2. Estevez-Garcia, J.A.; Schilmann, A.; Riojas-Rodriguez, H.; Berrueta, V.; Blanco, S.; Villasenor-Lozano, C.G.; Flores-Ramirez, R.; Cortez-Lugo, M.; Perez-Padilla, R. Women exposure to household air pollution after an improved cookstove program in rural San Luis Potosi, Mexico. Sci. Total Environ. 2020, 702, 134456. [CrossRef] [PubMed]

3. Wang, G.Y.; Wang, Y.; Yin, W.J.; Xu, T.; Hu, C.; Cheng, J.; Hou, J.; He, Z.Y.; Yuan, J. Seasonal exposure to PM 2.5 -bound polycyclic aromatic hydrocarbons and estimated lifetime risk of cancer: A pilot study. Sci. Total Environ. 2020, 702, 135056. [CrossRef] [PubMed]

4. Zhang, Y.P.; Mo, J.H.; Weschler, C.J. Reducing Health Risks from Indoor Exposures in Rapidly Developing Urban China. Environ. Health Persp. 2013, 121, 751-755. [CrossRef] [PubMed]

5. Rauert, C.; Lazarov, B.; Harrad, S.; Covaci, A.; Stranger, M. Areview of chamber experiments for determining specific emission rates and investigating migration pathways of flame retardants. Atmos. Environ. 2014, 82, 44-55. [CrossRef]

6. Chen, Y.Y.; Song, Y.Y.; Chen, Y.J.; Zhang, Y.H.; Li, R.J.; Wang, Y.J.; Qi, Z.H.; Chen, Z.F.; Cai, Z.W. Contamination profiles and potential health risks of organophosphate flame retardants in $\mathrm{PM}_{2.5}$ from Guangzhou and Taiyuan, China. Environ. Int. 2020, 134, 105343. [CrossRef]

7. Hu, Q.; Xu, L.; Liu, Y.; Zeng, X.; Yu, Z. Co-occurrence and distribution of organophosphate tri- and di-esters in indoor dust from different indoor environments in Guangzhou and their potential human health risk. Environ. Pollut. 2020, 262, 114311. [CrossRef]

8. Moller, A.; Sturm, R.; Xie, Z.Y.; Cai, M.H.; He, J.F.; Ebinghaus, R. Organophosphorus Flame Retardants and Plasticizers in Airborne Particles over the Northern Pacific and Indian Ocean toward the Polar Regions: Evidence for Global Occurrence. Environ. Sci. Technol. 2012, 46, 3127-3134. [CrossRef] [PubMed]

9. Chung, H.W.; Ding, W.H. Determination of organophosphate flame retardants in sediments by microwave-assisted extraction and gas chromatography-mass spectrometry with electron impact and chemical ionization. Anal. Bioanal. Chem. 2009, 395, $2325-2334$. [CrossRef]

10. Regnery, J.; Puttmann, W. Occurrence and fate of organophosphorus flame retardants and plasticizers in urban and remote surface waters in Germany. Water Res. 2010, 44, 4097-4104. [CrossRef]

11. Bollmann, U.E.; Moler, A.; Xie, Z.Y.; Ebinghaus, R.; Einax, J.W. Occurrence and fate of organophosphorus flame retardants and plasticizers in coastal and marine surface waters. Water Res. 2012, 46, 531-538. [CrossRef]

12. Brandsma, S.H.; de Boer, J.; van Velzen, M.J.; Leonards, P.E. Organophosphorus flame retardants (PFRs) and plasticizers in house and car dust and the influence of electronic equipment. Chemosphere 2014, 116, 3-9. [CrossRef] [PubMed]

13. Abdallah, M.A.; Covaci, A. Organophosphate Flame Retardants in Indoor Dust from Egypt: Implications for Human Exposure. Environ. Sci. Technol. 2014, 48, 4782-4789. [CrossRef]

14. Mihajlovic, I.; Miloradov, M.V.; Fries, E. Application of Twisselmann Extraction, SPME, and GC-MS To Assess Input Sources for Organophosphate Esters into Soil. Environ. Sci. Technol. 2011, 45, 2264-2269. [CrossRef]

15. Kim, J.W.; Isobe, T.; Chang, K.H.; Amano, A.; Maneja, R.H.; Zamora, P.B.; Siringan, F.P.; Tanabe, S. Levels and distribution of organophosphorus flame retardants and plasticizers in fishes from Manila Bay, the Philippines. Environ. Pollut. 2011, 159, 3653-3659. [CrossRef] [PubMed]

16. Ma, J.; Zhu, H.K.; Kannan, K. Organophosphorus Flame Retardants and Plasticizers in Breast Milk from the United States. Environ. Sci. Technol. Lett. 2019, 6, 525-531. [CrossRef] [PubMed]

17. Tao, L.; Kannan, K.; Wong, C.M.; Arcaro, K.F.; Butenhoff, J.L. Perfluorinated compounds in human milk from Massachusetts, USA. Environ. Sci. Technol. 2008, 42, 3096-3101. [CrossRef] [PubMed]

18. She, J.W.; Holden, A.; Sharp, M.; Tanner, M.; Williams-Derry, C.; Hooper, K. Polybrominated diphenyl ethers (PBDEs) and polychlorinated biphenyls (PCBs) in breast milk from the Pacific Northwest. Chemosphere 2007, 67, S307-S317. [CrossRef] [PubMed]

19. van der Veen, I.; de Boer, J. Phosphorus flame retardants: Properties, production, environmental occurrence, toxicity and analysis. Chemosphere 2012, 88, 1119-1153. [CrossRef] [PubMed]

20. Saillenfait, A.M.; Ndaw, S.; Robert, A.; Sabate, J.P. Recent biomonitoring reports on phosphate ester flame retardants: A short review. Arch. Toxicol. 2018, 92, 2749-2778. [CrossRef]

21. Zhang, Q.; Ji, C.Y.; Yin, X.H.; Yan, L.; Lu, M.Y.; Zhao, M.R. Thyroid hormone-disrupting activity and ecological risk assessment of phosphorus-containing flame retardants by in vitro, in vivo and in silico approaches. Environ. Pollut. 2016, 210, 27-33. [CrossRef] [PubMed]

22. Noyes, P.D.; Haggard, D.E.; Gonnerman, G.D.; Tanguay, R.L. Advanced Morphological—Behavioral Test Platform Reveals Neurodevelopmental Defects in Embryonic Zebrafish Exposed to Comprehensive Suite of Halogenated and Organophosphate Flame Retardants. Toxicol. Sci. 2015, 145, 177-195. [CrossRef]

23. Kojima, H.; Takeuchi, S.; Itoh, T.; Iida, M.; Kobayashi, S.; Yoshida, T. In vitro endocrine disruption potential of organophosphate flame retardants via human nuclear receptors. Toxicology 2013, 314, 76-83. [CrossRef] 
24. Yuan, L.L.; Li, J.S.; Zha, J.M.; Wang, Z.J. Targeting neurotrophic factors and their receptors, but not cholinesterase or neurotransmitter, in the neurotoxicity of TDCPP in Chinese rare minnow adults (Gobiocypris rarus). Environ. Pollut. 2016, 208, 670-677. [CrossRef] [PubMed]

25. Stapleton, H.M.; Klosterhaus, S.; Eagle, S.; Fuh, J.; Meeker, J.D.; Blum, A.; Webster, T.F. Detection of Organophosphate Flame Retardants in Furniture Foam and US House Dust. Environ. Sci. Technol. 2009, 43, 7490-7495. [CrossRef]

26. Yang, Y.; Xiao, Y.; Chang, Y.G.; Cui, Y.B.; Klobucar, G.; Li, M. Intestinal damage, neurotoxicity and biochemical responses caused by tris (2-chloroethyl) phosphate and tricresyl phosphate on earthworm. Ecotoxicol. Environ. Saf. 2018, 158, 78-86. [CrossRef] [PubMed]

27. Wang, Y.; Yao, Y.M.; Han, X.X.; Li, W.H.; Zhu, H.K.; Wang, L.; Sun, H.W.; Kannan, K. Organophosphate di- and tri-esters in indoor and outdoor dust from China and its implications for human exposure. Sci. Total Environ. 2020, 700, 134502. [CrossRef]

28. Li, H.L.; Liu, L.Y.; Zhang, Z.F.; Ma, W.L.; Sverko, E.; Zhang, Z.; Song, W.W.; Sun, Y.; Li, Y.F. Semi-volatile organic compounds in infant homes: Levels, influence factors, partitioning, and implications for human exposure. Environ. Pollut. 2019, 251, 609-618. [CrossRef] [PubMed]

29. Liu, L.Y.; He, K.; Hites, R.A.; Salamova, A. Hair and Nails as Noninvasive Biomarkers of Human Exposure to Brominated and Organophosphate Flame Retardants. Environ. Sci. Technol. 2016, 50, 3065-3073. [CrossRef] [PubMed]

30. Butt, C.M.; Congleton, J.; Hoffman, K.; Fang, M.L.; Stapleton, H.M. Metabolites of Organophosphate Flame Retardants and 2-Ethylhexyl Tetrabromobenzoate in Urine from Paired Mothers and Toddlers. Environ. Sci. Technol. 2014, 48, 10432-10438. [CrossRef]

31. Butt, C.M.; Hoffman, K.; Chen, A.; Lorenzo, A.; Congleton, J.; Stapleton, H.M. Regional comparison of organophosphate flame retardant (PFR) urinary metabolites and tetrabromobenzoic acid (TBBA) in mother-toddler pairs from California and New Jersey. Environ. Int. 2016, 94, 627-634. [CrossRef]

32. Van den Eede, N.; Maho, W.; Erratico, C.; Neels, H.; Covaci, A. First insights in the metabolism of phosphate flame retardants and plasticizers using human liver fractions. Toxicol. Lett. 2013, 223, 9-15. [CrossRef] [PubMed]

33. Van den Eede, N.; Tomy, G.; Tao, F.; Halldorson, T.; Harrad, S.; Neels, H.; Covaci, A. Kinetics of tris (1-chloro-2-propyl) phosphate (TCIPP) metabolism in human liver microsomes and serum. Chemosphere 2016, 144, 1299-1305. [CrossRef]

34. Nguyen, L.V.; Diamond, M.L.; Venier, M.; Stubbings, W.A.; Romanak, K.; Bajard, L.; Melymuk, L.; Jantunen, L.M.; Arrandale, V.H. Exposure of Canadian electronic waste dismantlers to flame retardants. Environ. Int. 2019, 129, 95-104. [CrossRef]

35. Zheng, X.B.; Xu, F.C.; Chen, K.H.; Zeng, Y.H.; Luo, X.J.; Chen, S.J.; Mai, B.X.; Covaci, A. Flame retardants and organochlorines in indoor dust from several e-waste recycling sites in South China: Composition variations and implications for human exposure. Environ. Int. 2015, 78, 1-7. [CrossRef]

36. Wu, M.; Yu, G.; Cao, Z.G.; Wu, D.K.; Liu, K.; Deng, S.B.; Huang, J.; Wang, B.; Wang, Y.J. Characterization and human exposure assessment of organophosphate flame retardants in indoor dust from several microenvironments of Beijing, China. Chemosphere 2016, 150, 465-471. [CrossRef]

37. Cequier, E.; Ionas, A.C.; Covaci, A.; Marce, R.M.; Becher, G.; Thomsen, C. Occurrence of a Broad Range of Legacy and Emerging Flame Retardants in Indoor Environments in Norway. Environ. Sci. Technol. 2014, 48, 6827-6835. [CrossRef]

38. Mendelsohn, E.; Hagopian, A.; Hoffman, K.; Butt, C.M.; Lorenzo, A.; Congleton, J.; Webster, T.F.; Stapleton, H.M. Nail polish as a source of exposure to triphenyl phosphate. Environ. Int. 2016, 86, 45-51. [CrossRef]

39. Ali, N.; Ali, L.; Mehdi, T.; Dirtu, A.C.; Al-Shammari, F.; Neels, H.; Covaci, A. Levels and profiles of organochlorines and flame retardants in car and house dust from Kuwait and Pakistan: Implication for human exposure via dust ingestion. Environ. Int. 2013, 55, 62-70. [CrossRef]

40. Ali, N.; Dirtu, A.C.; Van den Eede, N.; Goosey, E.; Harrad, S.; Neels, H.; t Mannetje, A.; Coakley, J.; Douwes, J.; Covaci, A. Occurrence of alternative flame retardants in indoor dust from New Zealand: Indoor sources and human exposure assessment. Chemosphere 2012, 88, 1276-1282. [CrossRef]

41. Zhou, L.; Hiltscher, M.; Puttmann, W. Occurrence and human exposure assessment of organophosphate flame retardants in indoor dust from various microenvironments of the Rhine/Main region, Germany. Indoor Air 2017, 27, 1113-1127. [CrossRef]

42. Ali, N.; Eqani, S.A.M.A.S.; Ismail, I.M.I.; Malarvannan, G.; Kadi, M.W.; Albar, H.M.S.; Rehan, M.; Covaci, A. Brominated and organophosphate flame retardants in indoor dust of Jeddah, Kingdom of Saudi Arabia: Implications for human exposure. Sci. Total Environ. 2016, 569, 269-277. [CrossRef]

43. Mizouchi, S.; Ichiba, M.; Takigami, H.; Kajiwara, N.; Takamuku, T.; Miyajima, T.; Kodama, H.; Someya, T.; Ueno, D. Exposure assessment of organophosphorus and organobromine flame retardants via indoor dust from elementary schools and domestic houses. Chemosphere 2015, 123, 17-25. [CrossRef]

44. Bergh, C.; Torgrip, R.; Emenius, G.; Ostman, C. Organophosphate and phthalate esters in air and settled dust-A multi-location indoor study. Indoor Air 2011, 21, 67-76. [CrossRef]

45. Brommer, S.; Harrad, S. Sources and human exposure implications of concentrations of organophosphate flame retardants in dust from UK cars, classrooms, living rooms, and offices. Environ. Int. 2015, 83, 202-207. [CrossRef]

46. Yadav, I.C.; Devi, N.L.; Zhong, G.C.; Li, J.; Zhang, G.; Covaci, A. Occurrence and fate of organophosphate ester flame retardants and plasticizers in indoor air and dust of Nepal: Implication for human exposure. Environ. Pollut. 2017, 229, 668-678. [CrossRef]

47. Hartmann, P.C.; Burgi, D.; Giger, W. Organophosphate flame retardants and plasticizers in indoor air. Chemosphere 2004, 57, 781-787. [CrossRef] 
48. Liu, X.T.; Chen, D.; Yu, Y.J.; Zeng, X.W.; Li, L.Z.; Xie, Q.T.; Yang, M.; Wu, Q.Z.; Dong, G.H. Novel Organophosphate Esters in Airborne Particulate Matters: Occurrences, Precursors, and Selected Transformation Products (vol 54, pg 13771, 2020). Environ. Sci. Technol. 2021, 55, 2170. [CrossRef]

49. Wong, F.; de Wit, C.A.; Newton, S.R. Concentrations and variability of organophosphate esters, halogenated flame retardants, and polybrominated diphenyl ethers in indoor and outdoor air in Stockholm, Sweden. Environ. Pollut. 2018, 240, 514-522. [CrossRef]

50. Kim, U.J.; Wang, Y.; Li, W.H.; Kannan, K. Occurrence of and human exposure to organophosphate flame retardants/plasticizers in indoor air and dust from various microenvironments in the United States. Environ. Int. 2019, 125, 342-349. [CrossRef]

51. Tran, L.K.; He, C.; Phuc, D.H.; Toms, L.M.L.; Wang, X.Y.; Xiu, M.; Mueller, J.F.; Covaci, A.; Morawska, L.; Thai, P.K. Monitoring the levels of brominated and organophosphate flame retardants in passenger cars: Utilisation of car air filters as active samplers J. Environ. Sci. 2020, 91, 142-150. [CrossRef]

52. Andresen, J.A.; Grundmann, A.; Bester, K. Organophosphorus flame retardants and plasticisers in surface waters. Sci. Total Environ. 2004, 332, 155-166. [CrossRef]

53. He, C.; Wang, X.Y.; Thai, P.; Baduel, C.; Gallen, C.; Banks, A.; Bainton, P.; English, K.; Mueller, J.F. Organophosphate and brominated flame retardants in Australian indoor environments: Levels, sources, and preliminary assessment of human exposure. Environ. Pollut. 2018, 235, 670-679. [CrossRef]

54. Stapleton, H.M.; Klosterhaus, S.; Keller, A.; Ferguson, P.L.; van Bergen, S.; Cooper, E.; Webster, T.F.; Blum, A. Identification of Flame Retardants in Polyurethane Foam Collected from Baby Products. Environ. Sci. Technol. 2011, 45, 5323-5331. [CrossRef]

55. Stapleton, H.M.; Sharma, S.; Getzinger, G.; Ferguson, P.L.; Gabriel, M.; Webster, T.F.; Blum, A. Novel and High Volume Use Flame Retardants in US Couches Reflective of the 2005 PentaBDE Phase Out. Environ. Sci. Technol. 2012, 46, 13432-13439. [CrossRef]

56. Sugeng, E.J.; de Cock, M.; Leonards, P.E.G.; van de Bor, M. Toddler behavior, the home environment, and flame retardant exposure. Chemosphere 2020, 252, 126588. [CrossRef]

57. Bjorklund, J.; Isetun, S.; Nilsson, U. Selective determination of organophosphate flame retardants and plasticizers in indoor air by gas chromatography, positive-ion chemical ionization and collision-induced dissociation mass spectrometry. Rapid Commun. Mass Spectrom. 2004, 18, 3079-3083. [CrossRef]

58. He, C.T.; Zheng, J.; Qiao, L.; Chen, S.J.; Yang, J.Z.; Yuan, J.G.; Yang, Z.Y.; Mai, B.X. Occurrence of organophosphorus flame retardants in indoor dust in multiple microenvironments of southern China and implications for human exposure. Chemosphere 2015, 133, 47-52. [CrossRef] [PubMed]

59. Marklund, A.; Andersson, B.; Haglund, P. Organophosphorus flame retardants and plasticizers in air from various indoor environments. J. Environ. Monit. 2005, 7, 814-819. [CrossRef] [PubMed]

60. David, M.D.; Seiber, J.N. Analysis of organophosphate hydraulic fluids in US Air Force base soils. Arch. Environ. Contam. Toxicol. 1999, 36, 235-241. [CrossRef]

61. Sun, Y.; Gong, X.; Lin, W.L.; Liu, Y.; Wang, Y.J.; Wu, M.H.; Kannan, K.; Ma, J. Metabolites of organophosphate ester flame retardants in urine from Shanghai, China. Environ. Res. 2018, 164, 507-515. [CrossRef]

62. Burger, J.; Fossi, C.; McClellan-Green, P.; Orlando, E.F. Methodologies, bioindicators, and biomarkers for assessing gender-related differences in wildlife exposed to environmental chemicals. Environ. Res. 2007, 104, 135-152. [CrossRef]

63. Wang, Q.W.; Lam, J.C.W.; Man, Y.C.; Lai, N.L.S.; Kwok, K.Y.; Guo, Y.Y.; Lam, P.K.S.; Zhou, B.S. Bioconcentration, metabolism and neurotoxicity of the organophorous flame retardant 1,3-dichloro 2-propyl phosphate (TDCPP) to zebrafish. Aquat. Toxicol. 2015, 158, 108-115. [CrossRef]

64. Thomas, M.B.; Stapleton, H.M.; Dills, R.L.; Violette, H.D.; Christakis, D.A.; Sathyanarayana, S. Demographic and dietary risk factors in relation to urinary metabolites of organophosphate flame retardants in toddlers. Chemosphere 2017, 185, 918-925. [CrossRef]

65. Yan, Z.F.; Feng, C.L.; Jin, X.W.; Liu, D.Q.; Hong, Y.J.; Qiao, Y.; Bai, Y.C.; Moon, H.B.; Qadeer, A.; Wu, F.C. In vitro metabolic kinetics of cresyl diphenyl phosphate (CDP) in liver microsomes of crucian carp (Carassius carassius). Environ. Pollut. 2021, 274, 116586. [CrossRef]

66. Kim, U.J.; Kannan, K. Occurrence and Distribution of Organophosphate Flame Retardants/Plasticizers in Surface Waters, Tap Water, and Rainwater: Implications for Human Exposure. Environ. Sci. Technol. 2018, 52, 5625-5633. [CrossRef]

67. Hoffman, K.; Gearhart-Serna, L.; Lorber, M.; Webster, T.F.; Stapleton, H.M. Estimated Tris(1,3-dichloro-2-propyl) Phosphate Exposure Levels for US Infants Suggest Potential Health Risks. Environ. Sci. Technol. Lett. 2017, 4, 334-338. [CrossRef]

68. Xu, F.C.; Garcia-Bermejo, A.; Malarvannan, G.; Gomara, B.; Neels, H.; Covaci, A. Multi-contaminant analysis of organophosphate and halogenated flame retardants in food matrices using ultrasonication and vacuum assisted extraction, multi-stage cleanup and gas chromatography-mass spectrometry. J. Chromatogr. A 2015, 1401, 33-41. [CrossRef]

69. Zheng, X.B.; Xu, F.C.; Luo, X.J.; Mai, B.X.; Covaci, A. Phosphate flame retardants and novel brominated flame retardants in home-produced eggs from an e-waste recycling region in China. Chemosphere 2016, 150, 545-550. [CrossRef] [PubMed]

70. Zhang, X.L.; Zou, W.; Mu, L.; Chen, Y.M.; Ren, C.X.; Hu, X.G.; Zhou, Q.X. Rice ingestion is a major pathway for human exposure to organophosphate flame retardants (OPFRs) in China. J. Hazard. Mater. 2016, 318, 686-693. [CrossRef] [PubMed] 
71. Zhang, T.; Xue, J.C.; Gao, C.Z.; Qiu, R.L.; Li, Y.X.; Li, X.; Huang, M.Z.; Kannan, K. Urinary Concentrations of Bisphenols and Their Association with Biomarkers of Oxidative Stress in People Living Near E-Waste Recycling Facilities in China. Environ. Sci. Technol. 2016, 50, 4045-4053. [CrossRef] [PubMed]

72. Ding, J.J.; Deng, T.Q.; Xu, M.M.; Wang, S.; Yang, F.X. Residuals of organophosphate esters in foodstuffs and implication for human exposure. Environ. Pollut. 2018, 233, 986-991. [CrossRef] [PubMed] 